Article

\title{
Spin-Singlet Transition in the Magnetic Hybrid Compound from a Spin-Crossover Fe(III) Cation and $\pi$-Radical Anion
}

\author{
Kazuyuki Takahashi ${ }^{1, *}$ (D), Takahiro Sakurai ${ }^{2}$, Wei-Min Zhang ${ }^{3}$, Susumu Okubo ${ }^{3}$, \\ Hitoshi Ohta ${ }^{3}$, Takashi Yamamoto ${ }^{4}$, Yasuaki Einaga ${ }^{4}$ and Hatsumi Mori ${ }^{5}$ \\ 1 Department of Chemistry, Graduate School of Science, Kobe University, 1-1 Rokkodai-cho, Nada-ku, Kobe, \\ Hyogo 657-8501, Japan \\ 2 Research Facility Center for Science and Technology, Kobe University, 1-1 Rokkodai-cho, Nada-ku, Kobe, \\ Hyogo 657-8501, Japan; tsakurai@kobe-u.ac.jp \\ 3 Molecular Photoscience Research Center, Kobe University, 1-1 Rokkodai-cho, Nada-ku, Kobe, \\ Hyogo 657-8501, Japan; tmrhu@hotmail.com (W.-M.Z.); sokubo@kobe-u.ac.jp (S.O.); \\ hohta@kobe-u.ac.jp (H.O.) \\ 4 Department of Chemistry, Graduate School of Science and Technology, Keio University, 3-14-1 Hiyoshi, \\ Kohoku-ku, Yokohama, Kanagawa 223-8522, Japan; takyama@chem.keio.ac.jp (T.Y.); \\ einaga@chem.keio.ac.jp (Y.E.) \\ 5 Institute for Solid State Physics, The University of Tokyo, 5-1-5 Kashiwanoha, Kashiwa, Chiba 277-8581, \\ Japan; hmori@issp.u-tokyo.ac.jp \\ * Correspondence: ktaka@crystal.kobe-u.ac.jp; Tel.: +81-78-803-5691
}

Received: 5 July 2017; Accepted: 11 August 2017; Published: 16 August 2017

\begin{abstract}
To develop a new spin-crossover functional material, a magnetic hybrid compound $\left[\mathrm{Fe}(\mathrm{qsal})_{2}\right]\left[\mathrm{Ni}(\mathrm{mnt})_{2}\right]$ was designed and synthesized (Hqsal $=\mathrm{N}$-(8-quinolyl)salicylaldimine, $\mathrm{mnt}=$ maleonitriledithiolate). The temperature dependence of magnetic susceptibility suggested the coexistence of the high-spin (HS) Fe(III) cation and $\pi$-radical anion at room temperature and a magnetic transition below $100 \mathrm{~K}$. The thermal variation of crystal structures revealed that strong $\pi$-stacking interaction between the $\pi$-ligand in the $\left[\mathrm{Fe}(\mathrm{qsal})_{2}\right]$ cation and $\left[\mathrm{Ni}(\mathrm{mnt})_{2}\right]$ anion induced the distortion of an $\mathrm{Fe}(\mathrm{III})$ coordination structure and the suppression of a dimerization of the [Ni(mnt $\left.)_{2}\right]$ anion. Transfer integral calculations indicated that the magnetic transition below $100 \mathrm{~K}$ originated from a spin-singlet formation transformation in the $\left[\mathrm{Ni}(\mathrm{mnt})_{2}\right]$ dimer. The magnetic relaxation of Mössbauer spectra and large thermal variation of a $g$-value in electron paramagnetic resonance spectra below the magnetic transition temperature implied the existence of a magnetic correlation between $\mathrm{d}$-spin and $\pi$-spin.
\end{abstract}

Keywords: spin-crossover; $\pi$-radical; spin transition; spin-singlet formation; $\pi$-stacking interaction; magnetic correlation; Fe(III) complex; Ni dithiolene complex

\section{Introduction}

Spin-crossover (SCO) between a high-spin (HS) and low-spin (LS) state in a transition metal coordination compound is one of the molecular bistable phenomena responsive to various external stimuli such as temperature, pressure, light, magnetic field, and chemicals. Significant attention has been paid to SCO in a wide field of chemical sciences [1,2]. The SCO switches not only a spin-state, but also electronic state and coordination structure in a metal complex. Thus the utilization of electronic and structural transformation accompanying SCO can lead to potential applications of display, memory, sensing and electronic devices [3,4]. 
One of the emergent fields of SCO research in the last decade is the development of multifunctional compounds between SCO and other solid-state electronic properties such as conductivity [5-12], magnetism [13-23], and optical properties [24,25]. The goal of this research is that one can design and synthesize a molecular solid whose electronic property can be controlled by external stimuli. However, most reports concerning functional SCO compounds described the coexistence of both SCO and other electronic property, while the achievement of a synergy between these two properties is still very limited. Thus further investigation is required to design and synthesis of a new functional SCO hybrid compound.

Various factors are involved in the realization of the synergy between $\mathrm{SCO}$ and electronic property. Among them we emphasized the role of intermolecular interactions either between SCO molecules or between SCO and counterfunctional molecules in a functional SCO hybrid compound. In particular, intermolecular interactions between SCO molecules can contribute to the cooperativity in SCO behavior as well as the crystal engineering of an SCO hybrid compound. According to our strategy, we successfully developed the multifunctional SCO compounds, namely SCO conductors [5,7] and SCO magnets [22,23]. Among them, [ $\left.\mathrm{Fe}(\mathrm{Iqsal})_{2}\right]\left[\mathrm{Ni}(\mathrm{dmit})_{2}\right] \cdot \mathrm{CH}_{3} \mathrm{CN} \cdot \mathrm{H}_{2} \mathrm{O}$ [22] is the intriguing compound which exhibits the synergistic spin transition between $\mathrm{SCO}$ and spin-singlet formation of the paramagnetic $\pi$-radical anions (HIqsal $=N$-(8-quinolyl)-5-iodosalicylaldimine, $\mathrm{dmit}=4,5$-dithiolato-1,3-dithiole-2-thione). The crucial point of this synergy is that the halogen-bonding interactions between iodine-substituted SCO Fe(III) cation and paramagnetic $\pi$-radical is competed with the energy gain from the spin-singlet formation in the paramagnetic $\pi$-radical dimer. In contrast, for the mother compound [Fe(qsal $\left.)_{2}\right]\left[\mathrm{Ni}(\mathrm{dmit})_{2}\right] \cdot 2 \mathrm{CH}_{3} \mathrm{CN}$ [26] and its analogue $\left[\mathrm{Fe}\left(\mathrm{qsal}_{2}\right]\left[\mathrm{Ni}(\mathrm{dmise})_{2}\right] \cdot 2 \mathrm{CH}_{3} \mathrm{CN}\right.$ [27], the nickel dithiolene $\pi$-radical anions formed a spin-singlet dimer below room temperature and might contribute to the cooperative SCO transitions of the SCO Fe(III) cations through $\pi$-stacking interactions between $\pi$-ligand and $\mathrm{Ni}$ dithiolene anion (Hqsal $=\mathrm{N}$-(8-quinolyl)salicylaldimine, dmise $=4,5$-dithiolato-1,3-dithiole-2-selone).

Further efforts to develop new paramagnetic SCO compounds, we focused on a similar paramagnetic $\pi$-radical anion, $\left[\mathrm{Ni}(\mathrm{mnt})_{2}\right]^{-}$, which afforded magnetic compounds showing various magnetic behaviors [28] ( $\mathrm{mnt}=$ maleonitriledithiolate). Recently, Nihei et al. reported that the Fe(II) compound from the [Ni(mnt $)_{2}$ ] anion exhibited a synergistic multistep spin transition [15]. However, the Fe(III) compound with the $\left[\mathrm{Ni}(\mathrm{mnt})_{2}\right]$ anion has never been reported. To compare the crystal structure and magnetic properties with the above $\left[\mathrm{N}(\mathrm{dmit})_{2}\right]$ compounds, we selected the $\left[\mathrm{Fe}(\mathrm{qsal})_{2}\right]$ cation as a potential SCO cation. We report herein the preparation, crystal structures, and magnetic properties of $\left[\mathrm{Fe}(\mathrm{qsal})_{2}\right]\left[\mathrm{Ni}(\mathrm{mnt})_{2}\right] \mathbf{1}$ (Figure 1). Although the present compound did not show an SCO phenomenon, we found a spin-singlet formation transition of the $\left[\mathrm{Ni}(\mathrm{mnt})_{2}\right]$ dimer and a magnetic correlation between d-spin and $\pi$-spin in Mössbauer and electron paramagnetic resonance (EPR) spectra. All these features were attributed to a strong $\pi$-stacking interaction between $\pi$-ligand of the $\left[\mathrm{Fe}(\mathrm{qsal})_{2}\right]$ cation and $\left[\mathrm{Ni}(\mathrm{mnt})_{2}\right]$ anion.


Figure 1. Chemical structural formula of compound 1. 


\section{Results and Discussion}

\subsection{Synthesis}

$\left[\mathrm{Fe}(\mathrm{qsal})_{2}\right]\left[\mathrm{Ni}(\mathrm{mnt})_{2}\right]$ was prepared by the metathesis reaction between $[\mathrm{Fe}(\mathrm{qsal})]_{2} \mathrm{Cl} \cdot 1.5 \mathrm{H}_{2} \mathrm{O}[29]$ and $(\mathrm{TBA})\left[\mathrm{Ni}(\mathrm{mnt})_{2}\right]$ in acetonitrile (TBA = tetrabutylammonium cation). Recrystallization from acetonitrile gave stable, tiny black crystals. The composition of the complex was confirmed by microanalysis and X-ray single crystal structural analysis described below.

\subsection{Magnetic Susceptibility}

The temperature variation of magnetic susceptibility for compound $\mathbf{1}$ is shown in Figure 2a. The $\chi_{\mathrm{M}} T$ value for compound 1 at $300 \mathrm{~K}$ was $4.51 \mathrm{~cm}^{3} \cdot \mathrm{K} \cdot \mathrm{mol}^{-1}$. Since the spin-only $\chi_{\mathrm{M}} T$ values for the HS Fe(III) ion $(S=5 / 2)$ and paramagnetic $\left[\mathrm{Ni}(\mathrm{mnt})_{2}\right]$ anion $(S=1 / 2)$ are 4.375 and $0.375 \mathrm{~cm}^{3} \cdot \mathrm{K} \cdot \mathrm{mol}^{-1}$, respectively, the $\chi_{\mathrm{M}} T$ value at $300 \mathrm{~K}$ suggests that the compound contains the $\mathrm{HS} \mathrm{Fe}(\mathrm{III})$ ion and paramagnetic $\pi$-radical anion. On cooling the sample, the $\chi_{M} T$ products were gradually decreased and reached to $4.43 \mathrm{~cm}^{3} \cdot \mathrm{K} \cdot \mathrm{mol}^{-1}$ at $100 \mathrm{~K}$. Further lowering temperature, a relatively steep decrease in the $\chi_{\mathrm{M}} T$ product was observed, and then a narrow plateau of the $\chi_{\mathrm{M}} T$ of $4.20 \mathrm{~cm}^{3} \cdot \mathrm{K} \cdot \mathrm{mol}^{-1}$ appeared at around $35 \mathrm{~K}$, suggesting compound 1 exhibited a magnetic transition. Below $15 \mathrm{~K}$ the $\chi_{\mathrm{M}} T$ values were abruptly decreased probably due to zero-field splitting effect.

To gain an insight of the magnetic transition, the magnetic field dependence of magnetization was measured at $2.0 \mathrm{~K}$. The magnetization curve is shown in Figure $2 \mathrm{~b}$. The magnetization at $5 \mathrm{~T}$ was $4.70 \mu_{\mathrm{B}}$ and the curve seems to be similar to the calculated curve of $S=5 / 2$ by using the Brillouin function. This implies that the $\left[\mathrm{Ni}(\mathrm{mnt})_{2}\right]$ anion might change from a paramagnetic state to a non-magnetic one in the magnetic transition.



(a)

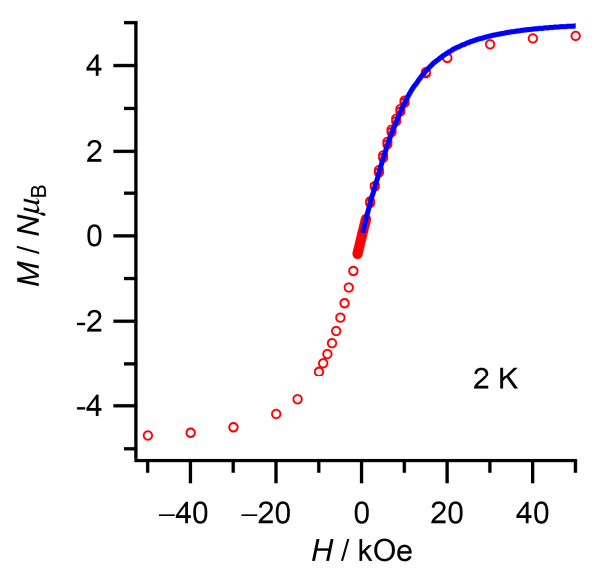

(b)

Figure 2. (a) $\chi_{\mathrm{M}} \mathrm{T}$ vs. $T$ products for 1 under a magnetic field of $0.5 \mathrm{~T}$ at a scan speed of $1 \mathrm{~K} \cdot \mathrm{min}^{-1}$; (b) Magnetic field dependence of magnetizations for 1 at $2 \mathrm{~K}$. Blue curve indicates the calculated magnetization curve with $S=5 / 2$ and $g=2$.

\subsection{Crystal Structural Analysis}

To investigate the structural changes below and above the magnetic transition, variable temperature single-crystal X-ray structural analyses for $\mathbf{1}$ were performed using a Rigaku CMF007 Mercury CCD diffractometer attached with a Japan Thermal Engineering helium gas-flow temperature controller. Crystallographic data are listed in Table 1. The crystal structures for $\mathbf{1}$ at all temperatures were isostructural and belonged to triclinic system with $P \overline{1}$. All asymmetric units contained one $\left[\mathrm{Fe}(\mathrm{qsal})_{2}\right]$ molecule and one $\left[\mathrm{Ni}(\mathrm{mnt})_{2}\right]$ molecule. 
Table 1. Crystallographic data for $\mathbf{1 .}$

\begin{tabular}{|c|c|c|c|}
\hline & \multicolumn{3}{|c|}{1} \\
\hline Formula & \multicolumn{3}{|c|}{$\mathrm{C}_{40} \mathrm{H}_{22} \mathrm{FeN}_{8} \mathrm{NiO}_{2} \mathrm{~S}_{4}$} \\
\hline Formula Weight & \multicolumn{3}{|c|}{889.45} \\
\hline Color & \multicolumn{3}{|c|}{ black } \\
\hline Dimension/mm & \multicolumn{3}{|c|}{$0.20 \times 0.20 \times 0.05$} \\
\hline $\mathrm{T} / \mathrm{K}$ & 293 & 100 & 25 \\
\hline Crystal system & triclinic & triclinic & triclinic \\
\hline Space Group & $P \overline{1}$ & $P \overline{1}$ & $P \overline{1}$ \\
\hline$a / \AA$ & $11.7638(6)$ & 11.5777(7) & $11.4218(11)$ \\
\hline$b / \AA$ & $13.5893(5)$ & $13.6154(4)$ & $13.7207(6)$ \\
\hline$c / \AA$ & $14.1000(10)$ & $13.9687(11)$ & $13.8041(17)$ \\
\hline$\alpha /^{\circ}$ & $65.962(11)$ & $66.134(8)$ & $67.123(12)$ \\
\hline$\beta /{ }^{\circ}$ & $85.184(14)$ & $84.758(12)$ & $84.938(18)$ \\
\hline$\gamma /{ }^{\circ}$ & $65.815(9)$ & $65.272(9)$ & $65.324(14)$ \\
\hline$V / \AA^{3}$ & $1868.5(3)$ & $1821.0(3)$ & $1804.0(4)$ \\
\hline Z & 2 & 2 & 2 \\
\hline$\rho_{\text {calcd. }} / \mathrm{g} \cdot \mathrm{cm}^{-3}$ & 1.581 & 1.622 & 1.637 \\
\hline$\mu(\mathrm{Mo}-\mathrm{K} \alpha)$ & 1.165 & 1.195 & 1.206 \\
\hline $2 \theta_{\max } /{ }^{\circ}$ & 55.13 & 54.99 & 55.02 \\
\hline Noflectionc (R. & 20124 & 17468 & 17099 \\
\hline No. Reflections $\left(R_{\text {int }}\right)$ & $(0.0214)$ & $(0.0365)$ & $(0.0347)$ \\
\hline & 8382 & 7972 & 7888 \\
\hline No. Observations $(I>2.00 \sigma(I))$ & $(6421)$ & (6636) & $(6604)$ \\
\hline No. Variables & 505 & 505 & 505 \\
\hline$R 1(I>2.00 \sigma(I))$ & 0.0468 & 0.0481 & 0.0553 \\
\hline$R$ (all data) & 0.0600 & 0.0567 & 0.0646 \\
\hline $\mathrm{w} R 2$ (all data) & 0.1427 & 0.1309 & 0.1231 \\
\hline Recidual ectron dencitu $/ 0 \AA-3$ & 0.90 & 1.14 & 1.05 \\
\hline Residual electron density/eA ${ }^{-3}$ & -0.66 & -0.93 & -1.22 \\
\hline Goodness of fit & 1.062 & 1.115 & 1.076 \\
\hline
\end{tabular}

\subsubsection{Molecular Structures in 1 at $293 \mathrm{~K}$}

The $\pi$-ligand molecule in the $\left[\mathrm{Fe}(\mathrm{qsal})_{2}\right]$ molecule was coordinated to a central $\mathrm{Fe}$ atom as a tridentate chelate ligand and thus two coordinated ligand molecules were arranged in an almost perpendicular manner (Figure 3a). The selected coordination bond lengths, distortion parameters, and angles for 1 along with those of the HS and LS [Fe(qsal $)_{2}$ ] cations in the [Ni(dmise $)_{2}$ ] compound [27] are listed in Table 2. As compared with the coordination bond lengths between $\mathbf{1}$ and $\left[\mathrm{Fe}(\mathrm{qsal})_{2}\right]$ cation, the $\mathrm{Fe}-\mathrm{O}$ and $\mathrm{Fe}-\mathrm{N}$ bond lengths for 1 were similar to those of the $\mathrm{HS}$ [Fe(qsal $)_{2}$ ] cation, indicating that the $\left[\mathrm{Fe}(\mathrm{qsal})_{2}\right]$ molecule in 1 was in the $\mathrm{HS} \mathrm{Fe}(\mathrm{III})$ state at $293 \mathrm{~K}$. On the other hand, the distortion parameters $\Sigma$ and $\Theta$ for 1 were much larger than those of the HS [Fe(qsal $)_{2}$ ] cation. The dihedral angles between the quinolyl and phenyl rings in two qsal ligands of 1 were $1.37\left(\eta_{1}\right)$ and $24.76^{\circ}\left(\eta_{2}\right)$. Thus one qsal ligand was planar, whereas the other one was nonplanar in $\mathbf{1}$. The dihedral angle $\eta_{2}$ was much larger than those of the HS and LS [Fe(qsal $)_{2}$ ] cations [27]. This suggests that the large distortion of a coordination structure may arise from the distortion of the nonplanar qsal ligand in the $\left[\mathrm{Fe}(\mathrm{qsal})_{2}\right]$ cation.

The molecular structure of the $\left[\mathrm{Ni}(\mathrm{mnt})_{2}\right]$ molecule is shown in Figure $3 \mathrm{~b}$. The selected bond lengths of the [Ni(mnt $\left.)_{2}\right]$ molecule for $\mathbf{1}$ along with the $\left[\mathrm{Ni}(\mathrm{mnt})_{2}\right]$ monoanion and dianion [30] are listed in Table 3. The mnt ligands were coordinated to a central $\mathrm{Ni}$ atom to form a square planar coordination structure. It is know that the charge of the $\left[\mathrm{Ni}(\mathrm{mnt})_{2}\right]$ molecule can be estimated by the $\mathrm{Ni}-\mathrm{S}$ bond lengths. As compared with the $\mathrm{Ni}-\mathrm{S}$ bond lengths of the $\left[\mathrm{Ni}(\mathrm{mnt})_{2}\right]$ monoanion and dianion, the [Ni(mnt $\left.)_{2}\right]$ molecule in $\mathbf{1}$ was ascribed to the monoanion. Therefore, compound $\mathbf{1}$ at $293 \mathrm{~K}$ consists of the HS Fe(III) cation $(S=5 / 2)$ and $\pi$-radical anion $(S=1 / 2)$. This is in good agreement with the suggestion of the existence of a $\pi$-anion radical from the magnetic susceptibility measurement. 




(a)

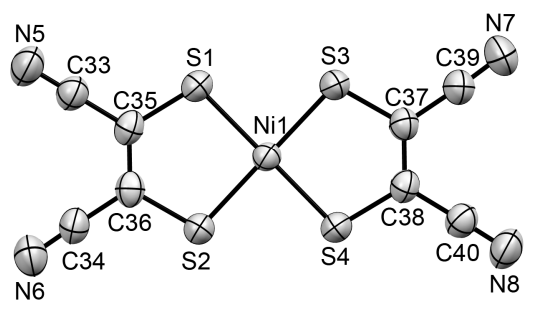

(b)

Figure 3. ORTEP drawings of 50\% probability with atomic numberings for compound 1 at $293 \mathrm{~K}$. (a) $\left[\mathrm{Fe}(\mathrm{qsal})_{2}\right]$ molecule; (b) $\left[\mathrm{Ni}(\mathrm{mnt})_{2}\right]$ molecule. Hydrogen atoms are omitted for clarity.

Table 2. Selected coordination bond lengths and distortion parameters of the $\left[\mathrm{Fe}(\mathrm{qsal})_{2}\right]$ molecule.

\begin{tabular}{cccccc}
\hline & \multicolumn{1}{c}{$\mathbf{1}$} & & HS [Fe(qsal) $\left.]_{2}\right]^{+}$ & LS [Fe(qsal) $\left._{2}\right]^{+}$ \\
\hline$T / \mathrm{K}$ & 293 & 100 & 25 & 273 & 200 \\
$\mathrm{Fe} 1-\mathrm{O} 1 / \AA$ & $1.9278(19)$ & $1.9371(18)$ & $1.942(2)$ & $1.918(2)$ & $1.8806(19)$ \\
$\mathrm{Fe} 1-\mathrm{O} 2 / \AA$ & $1.908(2)$ & $1.9131(18)$ & $1.914(2)$ & $1.909(3)$ & $1.882(2)$ \\
$\mathrm{Fe} 1-\mathrm{N} 1 / \AA$ & $2.097(2)$ & $2.101(2)$ & $2.100(3)$ & $2.114(3)$ & $1.950(3)$ \\
$\mathrm{Fe} 1-\mathrm{N} 2 / \AA$ & $2.195(2)$ & $2.196(2)$ & $2.195(3)$ & $2.151(2)$ & $1.979(2)$ \\
$\mathrm{Fe} 1-\mathrm{N} 3 / \AA$ & $2.131(2)$ & $2.132(2)$ & $2.132(3)$ & $2.126(3)$ & $1.948(3)$ \\
$\mathrm{Fe} 1-\mathrm{N} 4 / \AA$ & $2.136(2)$ & $2.129(2)$ & $2.128(3)$ & $2.133(3)$ & $1.972(3)$ \\
$\Sigma 1 /^{\circ}$ & $83.1(3)$ & $85.7(3)$ & $86.1(4)$ & $71.5(4)$ & $44.6(4)$ \\
$\Theta^{2} /^{\circ}$ & $149.1(4)$ & $151.0(4)$ & $151.6(5)$ & $121.1(5)$ & $54.9(5)$ \\
$\phi^{3} /^{\circ}$ & $162.17(8)$ & $161.97(8)$ & $162.16(11)$ & $166.35(11)$ & $176.59(11)$ \\
$\eta_{1} 4 /^{\circ}$ & 1.37 & 1.79 & 2.26 & 7.49 & 6.76 \\
$\eta_{2} 5 /^{\circ}$ & 24.76 & 26.66 & 27.46 & 7.94 & 5.88 \\
& this work & this work & this work & Ref. [27] & Ref. [27] \\
\hline
\end{tabular}

${ }^{1}$ The sum of the absolute differences of 12-bite angles of a first coordination sphere from $90^{\circ} .{ }^{2}$ The sum of the absolute differences of 24 angles of 8 triangle surfaces of a coordination octahedron from $60^{\circ}$. ${ }^{3}$ The angles of $\mathrm{N} 1-\mathrm{Fe} 1-\mathrm{N} 3 .{ }^{4}$ Dihedral angles between the quinolyl $(\mathrm{C} 24-\mathrm{C} 32, \mathrm{~N} 4)$ and phenyl $(\mathrm{C} 17-\mathrm{C} 22)$ rings. ${ }^{5}$ Dihedral angles between the quinolyl $(\mathrm{C} 8-\mathrm{C} 16, \mathrm{~N} 2)$ and phenyl (C1-C6) rings.

Table 3. Selected bond lengths of the $\left[\mathrm{Ni}(\mathrm{mnt})_{2}\right]$ molecule.

\begin{tabular}{|c|c|c|c|c|c|}
\hline & & 1 & & {$\left[\mathrm{Ni}(\mathrm{mnt})_{2}\right]^{-}$} & {$\left[\mathrm{Ni}(\mathrm{mnt})_{2}\right]^{2-}$} \\
\hline$T / K$ & 293 & 100 & 25 & & \\
\hline $\mathrm{Ni1}-\mathrm{S} 1 / \AA$ & $2.1466(8)$ & $2.1509(7)$ & $2.1466(10)$ & $2.147(3)^{1}$ & $2.176(1)^{1}$ \\
\hline $\mathrm{Ni1}-\mathrm{S} 2 / \AA$ & $2.1383(8)$ & $2.1432(7)$ & $2.1459(10)$ & $2.151(3)^{1}$ & $2.173(1)^{1}$ \\
\hline $\mathrm{Ni1}-\mathrm{S} 3 / \AA$ & $2.1340(8)$ & $2.1391(7)$ & $2.1376(10)$ & $2.148(3)^{1}$ & - \\
\hline $\mathrm{Ni1}-\mathrm{S} 4 / \AA$ & $2.1421(8)$ & $2.1469(7)$ & $2.1458(10)$ & $2.149(3)^{1}$ & - \\
\hline $\mathrm{S} 1-\mathrm{C} 35 / \AA$ & $1.718(3)$ & $1.718(3)$ & $1.708(4)$ & $1.727(10)^{1}$ & $1.732(4)^{1}$ \\
\hline $\mathrm{S} 2-\mathrm{C} 36 / \AA$ & $1.715(3)$ & $1.721(3)$ & $1.712(4)$ & $1.722(9)^{1}$ & $1.725(5)^{1}$ \\
\hline S3-C37/ & $1.715(3)$ & $1.723(2)$ & $1.722(4)$ & $1.705(10)^{1}$ & - \\
\hline S4-C38/ & $1.720(3)$ & $1.726(3)$ & $1.729(4)$ & $1.724(9)^{1}$ & - \\
\hline C35-C36/A & $1.349(4)$ & $1.360(4)$ & $1.374(5)$ & $1.367(12)^{1}$ & $1.360(7)^{1}$ \\
\hline \multirow[t]{2}{*}{ C $37-C 38 / \AA$} & $1.358(4)$ & $1.361(4)$ & $1.358(5)$ & $1.370(12)^{1}$ & - \\
\hline & this work & this work & this work & Ref. [30] & Ref. [30] \\
\hline
\end{tabular}

${ }^{1}$ The bond lengths corresponding to the atomic numberings of $\mathbf{1}$.

\subsubsection{Molecular Arrangement of $\mathbf{1}$ at $293 \mathrm{~K}$}

The molecular arrangement for $\mathbf{1}$ at $293 \mathrm{~K}$ is shown in Figure $4 \mathrm{a}-\mathrm{e}$ and the selected intermolecular distances are listed in Tables 4 and 5. The planar qsal ligand (C17-C32, N3, N4) of a $\left[\mathrm{Fe}(\mathrm{qsal})_{2}\right]$ cation was stacked with that of another neighboring $\left[\mathrm{Fe}(\mathrm{qsal})_{2}\right]$ cation related with the inversion symmetry 
(p in Figure $4 a$ ), to form a $\pi$-stacking $\left[\mathrm{Fe}(\mathrm{qsal})_{2}\right]$ dimer with a mean $\pi$-plane distance of $3.41 \AA$ (Table 4 ). On the other hand, there were $\pi$-stacking interactions both between the quinolyl rings $(\mathrm{C} 8-\mathrm{C} 16, \mathrm{~N} 2)$ ( $q$ in Figure $4 b$ ) and between the phenyl rings (C1-C6) ( $r$ in Figure $4 b$ ), where both rings belong to the nonplanar qsal ligand. Their mean $\pi$-plane distances were 3.35 and $3.50 \AA$, respectively (Table 4). Therefore, the $\left[\mathrm{Fe}(\mathrm{qsal})_{2}\right]$ dimers formed a two-dimensional (2D) $\pi$-stacking array parallel to the $b c$ plane (Figure 4a).



(a)

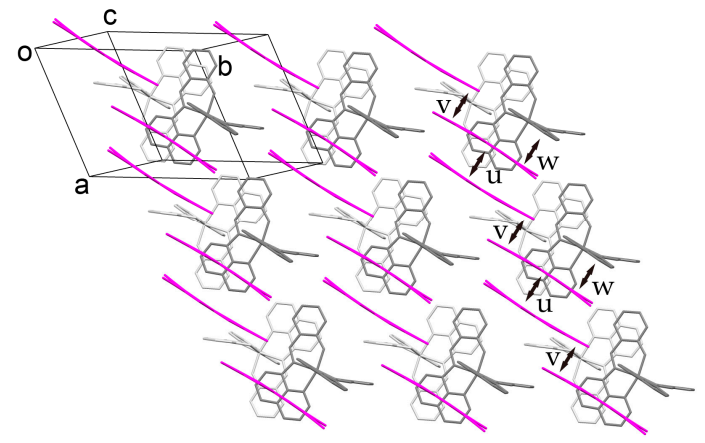

(c)

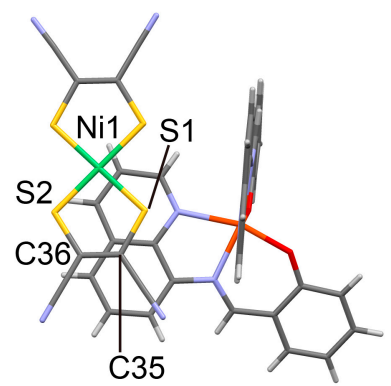

(e)

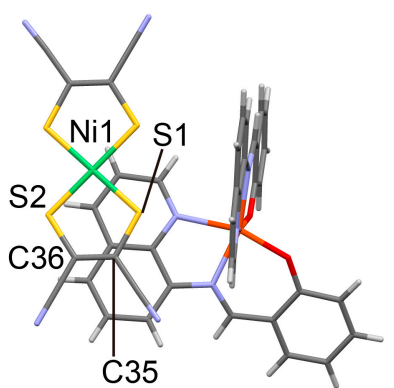

(f)

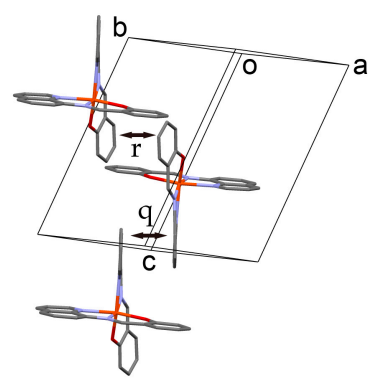

(b)

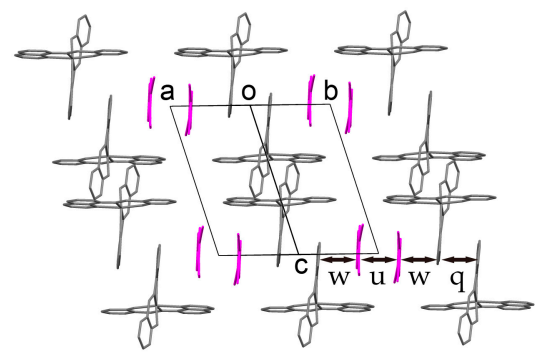

(d)

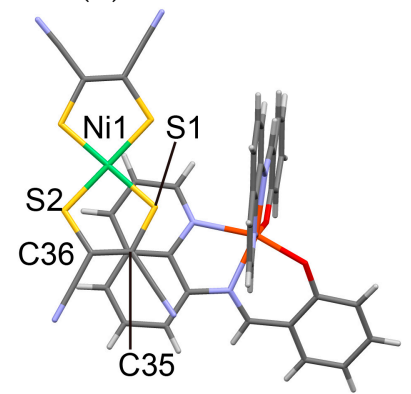

(g)

Figure 4. Crystal structure of 1 . (a) $2 \mathrm{D}$ molecular arrangement of the [Fe(qsal $\left.)_{2}\right]$ moleucle viewed along the direction perpendicular to the overlapped quinolyl plane at $293 \mathrm{~K}$; (b) $\pi$-stacking mode between the $\left[\mathrm{Fe}\left(\mathrm{qsal}_{2}\right]\right.$ dimers viewed along the direction parallel to the overlapped quinolyl plane at $293 \mathrm{~K}$; (c) Molecular arrangement of the $\left[\mathrm{Ni}(\mathrm{mnt})_{2}\right]$ molecule (magenta sticks) along with the [Fe(qsal $\left.)_{2}\right]$ molecule layer just below the $\left[\mathrm{Ni}(\mathrm{mnt})_{2}\right]$ layer at $293 \mathrm{~K}$; (d) Side view of $\pi$-stacking structure from the $\left[\mathrm{Ni}(\mathrm{mnt})_{2}\right]$ dimer and quinolyl rings perpendicular to the $a-b$ direction at $293 \mathrm{~K}$; Top views of the $\pi$-stacking between the [Ni(mnt $\left.)_{2}\right]$ and nonplanar qsal molecules at $293 \mathrm{~K}(\mathbf{e})$; at $100 \mathrm{~K}(\mathbf{f})$; at $25 \mathrm{~K}(\mathbf{g})$; Letters with double-headed arrows indicate the positions listed in Tables 4 and 5.

The $\left[\mathrm{Ni}(\mathrm{mnt})_{2}\right]$ anions also formed a face-to-face $\pi$-stacking dimer with a mean $\pi$-plane distance of $3.51 \AA$ ( $u$ in Figure $4 c)$. The [Ni(mnt) ${ }_{2}$ ] dimers were arranged along the $a$ axis by a small $\pi$-overlap with a $\pi$-plane separation of $3.20 \AA$ ( $v$ in Figure $4 \mathrm{c}$ ). With respect to the intermolecular interaction 
between the $\left[\mathrm{Fe}(\mathrm{qsal})_{2}\right]$ cation and $\left[\mathrm{Ni}(\mathrm{mnt})_{2}\right]$ anion, the five-membered dithiolene ring $(\mathrm{Ni1}, \mathrm{S} 1, \mathrm{~S} 2$, $\mathrm{C} 35, \mathrm{C} 36)$ in the $\left[\mathrm{Ni}(\mathrm{mnt})_{2}\right]$ anion overlapped the quinolyl ring $(\mathrm{C} 8-\mathrm{C} 16, \mathrm{~N} 2)$ in the nonplanar qsal ligand with a distance of 3.29-3.44 $\AA$ ( $w$ in Figure $4 \mathrm{c}$ and d). Although very similar $\pi$-overlaps were found in the $\left[\mathrm{Fe}(\mathrm{qsal})_{2}\right]\left[\mathrm{Ni}(\mathrm{dmise})_{2}\right]$ compound [27], the distances from the quinolyl plane to the S1 and C35 atoms in $\mathbf{1}$ (Figure 4e) were much shorter than the corresponding distances in the [Ni(dmise $\left.)_{2}\right]$ compounds (Table 5). This suggests a much stronger $\pi$-stacking interaction between the quinolyl ring and $\left[\mathrm{Ni}(\mathrm{mnt})_{2}\right]$ anion in $\mathbf{1}$. Since the molecular distortion in the nonplanar qsal ligand would originate from the present strong $\pi$-stacking interaction, the $\pi$-stacking interaction may induce the HS state in the $\left[\mathrm{Fe}(\mathrm{qsal})_{2}\right]$ cation. This $\pi$-stacking interaction gave a $1 \mathrm{D}$ alternate $\pi$-stacking column along the $a-b$ direction (Figure $4 \mathrm{~d}$ ). Accordingly, the crystal packing of the present compound 1 comprised 3D $\pi$-stacking interactions.

Table 4. Selected intermolecular distances $(\AA)$ in $\mathbf{1}$.

\begin{tabular}{|c|c|c|c|c|}
\hline & Position ${ }^{1}$ & & 1 & \\
\hline$T / K$ & & 293 & 100 & 25 \\
\hline $\mathrm{Fe}(q \mathrm{sal})_{2}$ intradimer & $\mathrm{p}$ & & & \\
\hline$\pi$-plane (qsal $\cdots$ qsal) & & 3.405 & 3.346 & 3.331 \\
\hline $\mathrm{Fe} 1 \cdots \mathrm{Fe} 1$ & & 6.672 & 6.640 & 6.671 \\
\hline $\mathrm{Fe}(q \mathrm{qsal})_{2}$ interdimer & $q, r$ & & & \\
\hline$\pi$-plane (quinolyl $\cdots$ quinolyl) & $\mathrm{q}$ & 3.347 & 3.297 & 3.302 \\
\hline $\mathrm{Fe} 1 \cdots \mathrm{Fe} 1$ & & 8.904 & 8.837 & 8.791 \\
\hline$\pi$-plane (phenyl $\cdots$ phenyl) & $\mathrm{r}$ & 3.501 & 3.388 & 3.372 \\
\hline $\mathrm{Fe} 1 \cdots \mathrm{Fe} 1$ & & 9.972 & 9.962 & 10.038 \\
\hline $\mathrm{Ni}(\mathrm{mnt})_{2}$ intradimer & $\mathrm{u}$ & & & \\
\hline$\pi$-plane & & 3.505 & 3.450 & 3.400 \\
\hline $\mathrm{Ni1} \cdots \mathrm{Ni1}$ & & 4.028 & 4.002 & 4.142 \\
\hline $\mathrm{Ni}(\mathrm{mnt})_{2}$ interdimer & $\mathrm{v}$ & & & \\
\hline$\pi$-plane & & 3.196 & 3.106 & 3.072 \\
\hline $\mathrm{Ni1} \cdots \mathrm{Ni1}$ & & 8.578 & 8.394 & 7.945 \\
\hline
\end{tabular}

${ }^{1}$ The positions corresponding to letters are shown in Figure 4.

Table 5. Intermolecular distances $(\AA)$ between the nickel dithiolene ring and qsal ligand $\left(\mathrm{w}^{1}\right)$.

\begin{tabular}{|c|c|c|c|c|c|}
\hline \multirow[b]{2}{*}{$T / K$} & \multicolumn{3}{|c|}{1} & \multicolumn{2}{|c|}{$\left[\mathrm{Ni}(\text { dmise })_{2}\right]$} \\
\hline & 293 & 100 & 25 & 273 & 200 \\
\hline 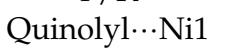 & 3.348 & 3.309 & 3.297 & 3.419 & 3.325 \\
\hline Quinolyl $\cdots$ S1 & 3.288 & 3.244 & 3.301 & $3.579^{2}$ & $3.519^{2}$ \\
\hline Quinolyl...C35 & 3.402 & 3.348 & 3.367 & $3.494^{2}$ & $3.498^{2}$ \\
\hline Quinolyl...C36 & 3.448 & 3.388 & 3.372 & $3.365^{2}$ & $3.404^{2}$ \\
\hline Quinolyl $\cdots \mathrm{S} 2$ & 3.448 & 3.393 & 3.362 & $3.297^{2}$ & $3.278^{2}$ \\
\hline \multirow[t]{2}{*}{ Fe1 $\cdots \mathrm{Ni1}$} & 6.214 & 6.223 & 6.433 & 6.591 & 6.282 \\
\hline & this work & this work & this work & Ref. [27] & Ref. [27] \\
\hline
\end{tabular}

${ }^{1}$ The position is shown in Figure $4 .{ }^{2}$ The bond lengths corresponding to the atomic numberings of $\mathbf{1}$.

\subsubsection{Thermal Variations of the Crystal Structure of $\mathbf{1}$}

The thermal variations of the bond lengths, angles, and intermolecular distances are listed in Tables $2-5$. There was no remarkable structural change in both the $\left[\mathrm{Fe}(\mathrm{qsal})_{2}\right]$ cation and the $\left[\mathrm{Ni}(\mathrm{mnt})_{2}\right]$ anion, suggesting that the $\mathrm{HS}$ state of the $\left[\mathrm{Fe}(\mathrm{qsal})_{2}\right]$ cation and valence state of the $\left[\mathrm{Ni}(\mathrm{mnt})_{2}\right]$ anion were retained in the whole temperature range measured. On the other hand, all intermolecular $\pi$-plane distances were shortened on lowering temperature from 293 to $100 \mathrm{~K}$, whereas some of the intermolecular $\pi$-plane distances were slightly lengthened on cooling from 100 to $25 \mathrm{~K}$ (Tables 4 and 5). Note that the $\mathrm{Ni} \cdots \mathrm{Ni}(\mathrm{u})$ and $\mathrm{Fe} \cdots \mathrm{Ni}(\mathrm{w})$ distances at $25 \mathrm{~K}$ were 0.14 and $0.21 \AA$ A longer than those at 
$100 \mathrm{~K}$ despite the shrinking of its $\pi$-plane distance. These structural variations may be related to the magnetic transition.

\subsection{Transfer Integrals Between the [Ni(mnt $\left.)_{2}\right]$ Molecules}

To provide an insight of the thermal variations in the magnetic exchange interaction between paramagnetic $\left[\mathrm{Ni}(\mathrm{mnt})_{2}\right]$ anions, transfer integrals were calculated based on the extended Hückel method [31]. The transfer integrals of the intradimer and interdimer for $\mathbf{1}$ at $293 \mathrm{~K}$ were 51.5 and $22.9 \mathrm{meV}$, respectively (Table 6). The overlap of LUMOs of the intradimer is two times larger than that of the interdimer, which rationalized the definition of the $\left[\mathrm{Ni}(\mathrm{mnt})_{2}\right]$ dimer. The transfer integrals of the interdimer were almost unchanged in spite of temperature variations. It should be noted that the transfer integral of the intradimer at $25 \mathrm{~K}$ is almost three times larger than that at 293 and $100 \mathrm{~K}$. Since the exchange coupling energy $J$ is known to be proportional to the square of a transfer integral [32,33], this exchange coupling energy at $25 \mathrm{~K}$ is about 10 times larger than that at $100 \mathrm{~K}$. The temperature range of the enhancement of exchange coupling energy was in good agreement with that of the magnetic transition. This clearly indicates that the magnetic transition below $100 \mathrm{~K}$ would originate from a spin-singlet formation of the paramagnetic $\left[\mathrm{Ni}(\mathrm{mnt})_{2}\right]$ dimer. Furthermore, this transition suggests the existence of an intermolecular interaction corresponding to the energy gain of the spin-singlet formation. As described in the previous section, on the spin-singlet formation transition, two remarkable intermolecular structural changes were observed in the $\left[\mathrm{Ni}(\mathrm{mnt})_{2}\right]$ dimer $(\mathrm{u})$ and the $\pi$-stacking structure between the $\left[\mathrm{Ni}(\mathrm{mnt})_{2}\right]$ anion and quinolyl ring in the nonplanar qsal ligand $(w)$. The former arises from the spin-singlet formation, the latter implies the variation of the intermolecular $\pi$-stacking interaction. The comparison between Figure $4 \mathrm{f}$ and $\mathrm{g}$ revealed that the $\left[\mathrm{Fe}(\mathrm{qsal})_{2}\right]$ cation and $\left[\mathrm{Ni}(\mathrm{mnt})_{2}\right]$ anion separate each other, indicating that the $\pi$-stacking interaction is weakened at $25 \mathrm{~K}$. Hence, the energy gain of the spin-singlet formation competed with the $\pi$-stacking interaction between the $\left[\mathrm{Ni}(\mathrm{mnt})_{2}\right]$ anion and quinolyl ring in the nonplanar qsal ligand.

Table 6. Transfer integrals $(\mathrm{m} \cdot \mathrm{eV})$ between the $\left[\mathrm{Ni}(\mathrm{mnt})_{2}\right]$ molecules in $\mathbf{1}$.

\begin{tabular}{ccccc}
\hline & Position $^{\mathbf{1}}$ & \multicolumn{1}{c}{$\mathbf{1}$} \\
\hline$T / \mathrm{K}$ & & 293 & 100 & 25 \\
Intradimer & $\mathrm{u}$ & 51.53 & 66.62 & 172.0 \\
Interdimer & $\mathrm{v}$ & 22.91 & 28.49 & 25.17 \\
\hline
\end{tabular}

${ }^{1}$ The positions corresponding to letters are shown in Figure 4.

\subsection{Electron Paramagnetic Resonance (EPR) Spectra}

To confirm the electronic states of the $\left[\mathrm{Fe}(\mathrm{qsal})_{2}\right]$ and $\left[\mathrm{Ni}(\mathrm{mnt})_{2}\right]$ for compound 1, the temperature dependence of electron paramagnetic resonance spectra for a polycrystalline sample of $\mathbf{1}$ was recorded in the temperature range of at 4.2-280 K (Figure 5a). The spectrum mainly consisted of a broad absorption at around $2 \mathrm{kOe}$, which can be ascribed to the $\mathrm{HS}\left[\mathrm{Fe}(\mathrm{qsal})_{2}\right]$ cation with a strong rhombic distortion [34]. On the other hand, there were no absorptions assigned to the LS [Fe(qsal $)_{2}$ ] cation and paramagnetic $\left[\mathrm{Ni}(\mathrm{mnt})_{2}\right]$ anion in the magnetic field range reported in the literature $[34,35]$. Note that no absorption ascribed to the LS [Fe(qsal $\left.)_{2}\right]$ cation appeared and moreover the $g$-values of the HS $\left[\mathrm{Fe}(\mathrm{qsal})_{2}\right]$ cation were largely shifted from $g=3.3$ to $g=4.0$ on cooling the sample from 100 to $40 \mathrm{~K}$ (Figure 5b). Thus, the magnetic transition did not arise from the SCO transition and the change in a $g$-value will be related to the spin-singlet formation in the $\left[\mathrm{Ni}(\mathrm{mnt})_{2}\right]$ dimer. Although the change in a coordination structure may lead to the shift of a $g$-value in a metal coordination complex, the structural variation of the $\left[\mathrm{Fe}(\mathrm{qsal})_{2}\right.$ ] cation from 100 to $25 \mathrm{~K}$ was smaller than that from 293 to $100 \mathrm{~K}$ and moreover the $g$-values were almost constant from $293 \mathrm{~K}$ to $100 \mathrm{~K}$. This means that the coordination structural change cannot account for the present large transformation in a $g$-value. Previously the $g$-value shifts were reported in the spin-Peierls compounds [36,37]. One possible explanation to shift a 
$g$-value in the present compound is that a magnetic exchange correlation between d-spin and $\pi$-spin might disappear as $\pi$-spins forms the spin-singlet. Additionally, it should be noted that no absorption assigned to the LS [Fe(qsal $)_{2}$ ] cation was observed even at $4.2 \mathrm{~K}$, indicating that the $\left[\mathrm{Fe}(\mathrm{qsal})_{2}\right]$ cation was in the HS state above $4.2 \mathrm{~K}$.

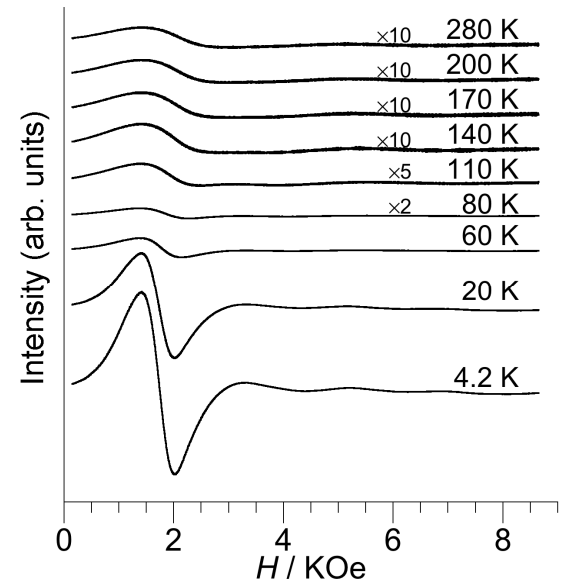

(a)



(b)

Figure 5. (a) Temperature dependence of electron paramagnetic resonance spectra for 1; (b) Temperature dependence of $g$-values for the absorption from the high-spin (HS) $\left[\mathrm{Fe}(\mathrm{qsal})_{2}\right]$ cation.

\subsection{Mössbauer Spectra}

To confirm the valence and spin states of the Fe ion for compound 1, the temperature valuable Mössbauer spectra for 1 were recorded at 15, 40, 100, and 293 K (Figure 6 and Table 7). The spectrum at $293 \mathrm{~K}$ consisted of mainly a broad asymmetric quadrupole doublet with isomer shift (IS) of 0.307(16) $\mathrm{mm} \cdot \mathrm{s}^{-1}$ and quadrupole splitting (QS) of $0.91(2) \mathrm{mm} \cdot \mathrm{s}^{-1}$. As compared with the $\left[\mathrm{Fe}(\mathrm{qsal})_{2}\right]$ complexes in the literature [29,38-40], the IS value is very similar to those of the HS [Fe(qsal $\left.)_{2}\right]$ species, whereas the QS value is larger than those of the HS species. This large QS value may arise from the distortion of a coordination octahedron. On cooling to $100 \mathrm{~K}$, the doublet spectrum was broadening. The IS shifted to a larger value of $0.48(4) \mathrm{mm} \cdot \mathrm{s}^{-1}$, whereas the QS was increased slightly. Further lowering temperatures very similar broad wing-like spectra without the splitting were recorded at 40 and $15 \mathrm{~K}$.

Note that the broad wing-like spectra below $100 \mathrm{~K}$ were indicative of a magnetic relaxation. Although a rapid exchange between the HS and LS states is known to one of the relaxation mechanisms in SCO complexes [41,42], the distorted and elongated HS coordination structure at $25 \mathrm{~K}$ and the absence of the LS signal in the EPR spectrum at $4.2 \mathrm{~K}$ would exclude this relaxation mechanism and thus all the spectra would be ascribed to the HS Fe(III) centers. As for another possible mechanism, the magnetic relaxation in HS Fe(III) compounds is known to arise from spin-spin relaxation related to the distance between the HS Fe(III) centers [43]. The adjacent distances between the Fe(III) centers in 1 were similar to those exhibiting spin-spin relaxation in the literature [43], but were almost temperature-independent (Table 4). This means that the spin-spin relaxation originating from the lengthening of the $\mathrm{Fe}(\mathrm{III})$ center distances would be excluded. Interestingly, since the spectrum broadening became remarkable in the temperature range of the formation of a spin-singlet $\left[\mathrm{Ni}(\mathrm{mnt})_{2}\right]$ dimer, the spin-spin relaxation on the Fe center might correlate with $\pi$-spin of the $\left[\mathrm{Ni}(\mathrm{mnt})_{2}\right]$ anion in the present compound. Further investigation needs to clarify the relaxation mechanism. 


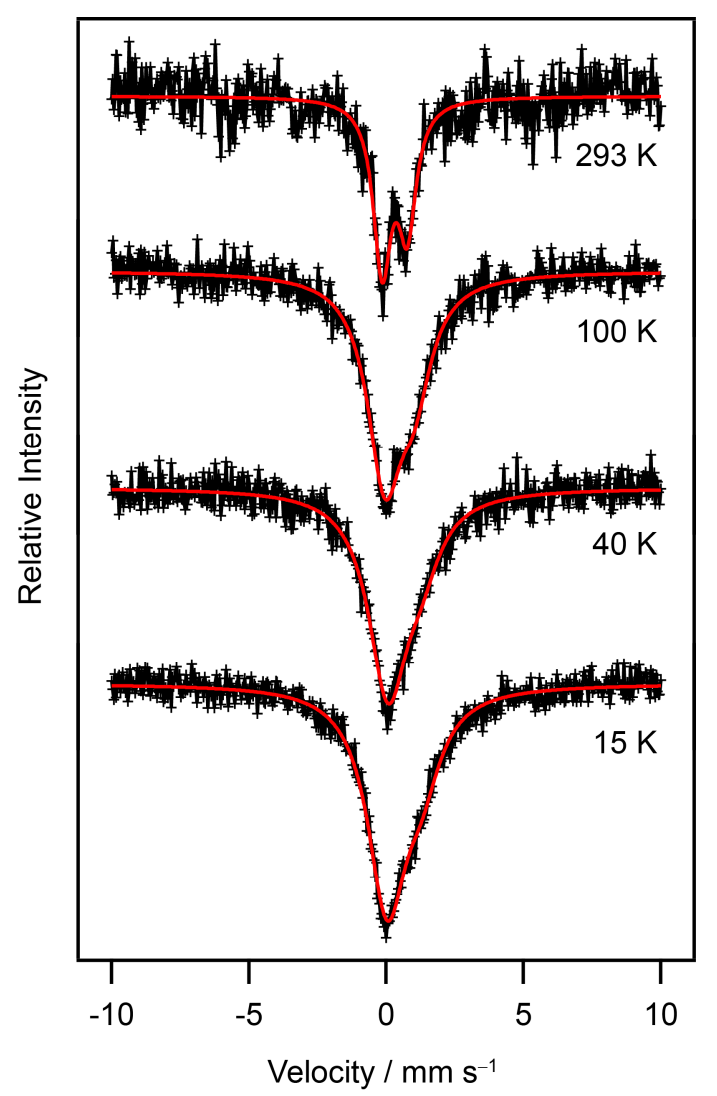

Figure 6. Mössbauer spectra for 1. Red curves indicate spectra simulated by using the parameters listed in Table 7.

Table 7. Temperature variations of Mössbauer parameters for $\mathbf{1}$.

\begin{tabular}{|c|c|c|c|c|c|}
\hline$T / K$ & Spin-State & Ratio & IS $1 / \mathrm{mm} \cdot \mathrm{s}^{-1}$ & $\mathrm{QS}^{2} / \mathrm{mm} \cdot \mathrm{s}^{-1}$ & $\mathrm{LW}^{3} / \mathrm{mm} \cdot \mathrm{s}^{-1}$ \\
\hline 293 & HS & $100 \%$ & $0.307(16)$ & $0.91(2)$ & $0.79(4)$ \\
\hline 100 & HS & $100 \%$ & $0.48(3)$ & $1.07(3)$ & $1.54(5)$ \\
\hline 40 & HS & $100 \%$ & $0.65(4)$ & $1.18(6)$ & $1.73(5)$ \\
\hline 15 & HS & $100 \%$ & $0.65(3)$ & $1.24(4)$ & $1.73(4)$ \\
\hline
\end{tabular}

\section{Materials and Methods}

All chemicals were purchased and used without further purification. [ $\left.\mathrm{Fe}(\mathrm{qsal})_{2}\right] \mathrm{Cl} \cdot 1.5 \mathrm{H}_{2} \mathrm{O}$ was prepared according to the literature [29].

\subsection{Synthesis of $\left[\mathrm{Fe}(q \mathrm{qal})_{2}\right]\left[\mathrm{Ni}(\mathrm{mnt})_{2}\right](\mathbf{1})$}

To a solution of [ $\left.\mathrm{Fe}(\mathrm{qsal})_{2}\right] \mathrm{Cl} \cdot 1.5 \mathrm{H}_{2} \mathrm{O}(122 \mathrm{mg}, 0.2 \mathrm{mmol})$ in $100 \mathrm{~mL}$ of acetonitrile was added a solution of (TBA)[Ni(mnt) $)_{2}(119 \mathrm{mg}, 0.2 \mathrm{mmol})$ in $20 \mathrm{~mL}$ of acetonitrile in one portion. After standing for several hours, black crystals were precipitated. Filtration and dry in air gave $84 \mathrm{mg}$ of compound 1 as black platelets ( $47 \%$ yield). The crystalline samples for the physical measurements below were obtained by recrystallization from acetonitrile.

Anal. Calcd. For $\mathrm{C}_{40} \mathrm{H}_{22} \mathrm{FeN}_{8} \mathrm{NiO}_{2} \mathrm{~S}_{4}: \mathrm{C}, 54.01 \% ; \mathrm{H}, 2.49 \%$;, $12.60 \%$. Found: $\mathrm{C}, 53.91 \% ; \mathrm{H}, 2.69 \%$; $\mathrm{N}, 12.40 \%$. 


\subsection{Physical Measurements}

Variable-temperature direct-current magnetic susceptibilities of polycrystalline samples (ca. $20 \mathrm{mg}$ ) fold in an aluminum foil were measured on a Quantum Design MPMS-XL magnetometer (San Diego, CA, USA) under a field of $0.5 \mathrm{~T}$ at a sweep speed of $1 \mathrm{~K} \cdot \mathrm{min}^{-1}$ in the temperature range of $2-300 \mathrm{~K}$. The sample magnetization data were obtained by the subtraction of background magnetization data for the aluminum foil from the measured data including the aluminum foil, and then the magnetic susceptibilities were corrected for diamagnetic contributions estimated by Pascal constants.

The Mössbauer spectra were recorded on a constant acceleration spectrometer with a source of ${ }^{57} \mathrm{Co} / \mathrm{Rh}$ in the transmission mode. The measurements at low temperature were performed with a closed-cycle helium refrigerator (Iwatani Co., Ltd. (Osaka, Japan)). Velocity was calibrated by using an $\alpha$-Fe standard. The obtained Mössbauer spectra were fitted with asymmetric Lorentzian doublets by the least squares fitting program (MossWinn (Version 4.0, Zoltán Klencsár, Budapest, Hungary)).

X-band $(\sim 9.5 \mathrm{GHz})$ electron paramagnetic resonance measurements have been performed on polycrystalline sample using a Bruker EMX081 ESR spectrometer (Yokohama, Japan) in the temperature region from 4.2 to $280 \mathrm{~K}$.

\subsection{Crystal Structure Determinations}

A platelet crystal was mounted in a polyimide loop. A Japan Thermal Engineering helium gas-flow temperature controller (Sagamihara, Japan) was used for the temperature variable measurements. All data were collected on a Rigaku CMF007 Mercury CCD diffractometer (Tokyo, Japan) using graphite monochromated Mo-K $\alpha$ radiation. All data collections and calculations were performed using CrystalClear (Rigaku (Tokyo, Japan)). The data were collected to a maximum $2 \theta$ value of about $55^{\circ}$. A total of 720 oscillation images were collected at $293 \mathrm{~K}$, whereas a total of 640 oscillation images were collected at 100 and $25 \mathrm{~K}$ due to the effect on the cold helium gas flow. Data were integrated and numerical absorption correction was applied. The CrystalStructure crystallographic software program package (Rigaku) was used to determine the unit cell parameters and crystal structures. The structure at $293 \mathrm{~K}$ was solved by direct methods and refined by full-matrix least-squares methods based on $F^{2}$ by using SHELXL Version 2016/6 (George Sheldrick, Göttingen, Germany). The atomic positions of the refined structure at $293 \mathrm{~K}$ were used as the initial structures at 100 and $25 \mathrm{~K}$ and refined by the same methods. All non-hydrogen atoms were refined anisotropically. Hydrogen atoms were generated by calculation and refined using the riding model. CCDC 1559560-1559562 contains the supplementary crystallographic data for this paper. These data can be obtained free of charge via http:/ / www.ccdc.cam.ac.uk/ conts/retrieving.html (or from the CCDC, 12 Union Road, Cambridge CB2 1EZ, UK; Fax: +44 1223 336033; E-mail: deposit@ccdc.cam.ac.uk).

\subsection{Transfer Integral Calculations}

The transfer integrals $(t)$ were calculated by the extended Hückel molecular orbital calculation method by using the lowest unoccupied molecular orbital (LUMO) of $\mathrm{Ni}(\mathrm{mnt})_{2}$ as the basis function within the tight-binding approximation [31]. The semiempirical parameters of $\mathrm{Ni}$ and C [44], S [45], $\mathrm{N}$ [46] for Slater-type atomic orbitals were taken from the literature. The $t$ between each pair of molecules was assumed to be proportional to the overlap integral $(S), t=E S$, where $E$ is a constant value of $-10.0 \mathrm{eV}$.

\section{Conclusions}

We reported the synthesis and characterization of $\pi$-d multi-spin magnetic compound $\left[\mathrm{Fe}(\mathrm{qsal})_{2}\right]\left[\mathrm{Ni}(\mathrm{mnt})_{2}\right]$. Unfortunately the $\mathrm{Fe}(\mathrm{III})$ center in the present compound was in the HS state and did not exhibit an SCO phenomenon, whereas a spin-singlet transition of the $\left[\mathrm{Ni}(\mathrm{mnt})_{2}\right]$ dimer was clearly evidenced. These two observations may arise from the stronger $\pi$-stacking interaction 
between the $\left[\mathrm{Ni}(\mathrm{mnt})_{2}\right]$ anion and [Fe(qsal $\left.)_{2}\right]$ cation than those in the $\left[\mathrm{Ni}(\mathrm{dmit})_{2}\right]$ and $\left[\mathrm{Ni}(\mathrm{dmise})_{2}\right]$ compounds [26,27]. Recently we found strong intermolecular interactions such as hydrogen-bonding and Coulomb interactions prevented Fe(III) complexes from exhibiting SCO [47,48]. As these observations are compared with functional SCO hybrid compounds $[5,7,22,23]$, the competition of intermolecular interactions between $\mathrm{SCO}$ and functional units play a key role in the development of a synergistic functional SCO compound. Moreover, magnetic relaxation in Mössbauer spectra and large $g$-value shift in EPR spectra were unexpectedly observed in the same temperature range of the spin-singlet formation. Although elucidation of their origins needs further investigation, they show the possibility that one spin-state can be probed by using the other spin in a multi-spin molecular system.

Supplementary Materials: The following are available online at www.mdpi.com/2304-6740/5/3/54/s1, Cif and cif-checked files.

Acknowledgments: This work was partially supported by a Grant-in-Aid for Scientific Research on Innovative Areas of Molecular Degrees of Freedom (No. 20110007) and JSPS KAKENHI Grant Number 25410068. Kazuyuki Takahashi is grateful to the Instrument Center of Institute for Molecular Science for the use of Rigaku CMF007 Mercury CCD system for X-ray crystal analyses.

Author Contributions: Kazuyuki Takahashi conceived, designed, performed the experiments, and analyzed the data; Takahiro Sakurai and Hitoshi Ohta contributed magnetic susceptibility measurements; Wei-Min Zhang and Susumu Okubo contributed EPR spectroscopy; Takashi Yamamoto and Yasuaki Einaga contributed Mössbauer spectroscopy; Hatsumi Mori contributed characterization of the compound; Kazuyuki Takahashi wrote the paper.

Conflicts of Interest: The authors declare no conflicts of interest.

\section{References}

1. Gütlich, P. Spin Crossover in Transition Metal Compounds; Goodwin, H.A., Ed.; Springer: Berlin/Heidelberg, Germany, 2004.

2. Halcrow, M.A. Spin-Crossover Materials; John Wiley \& Sons, Ltd.: Oxford, UK, 2013.

3. Bousseksou, A.; Molnár, G.; Salmon, L.; Nicolazzi, W. Molecular spin crossover phenomenon: Recent achievements and prospects. Chem. Soc. Rev. 2011, 40, 3313-3335. [CrossRef] [PubMed]

4. Gütlich, P.; Gaspar, A.B.; Garcia, Y. Spin state switching in iron coordination compounds. Beilstein J. Org. Chem. 2013, 9, 342-391. [CrossRef] [PubMed]

5. Takahashi, K.; Cui, H.-B.; Okano, Y.; Kobayashi, H.; Einaga, Y.; Sato, O. Electrical conductivity modulation coupled to a high-spin-low-spin conversion in the molecular system $\left[\mathrm{Fe}{ }^{\mathrm{III}}(\mathrm{qsal})_{2}\right]\left[\mathrm{Ni}(\mathrm{dmit})_{2}\right]_{3} \cdot \mathrm{CH}_{3} \mathrm{CN} \cdot \mathrm{H}_{2} \mathrm{O}$. Inorg. Chem. 2006, 45, 5739-5741. [CrossRef] [PubMed]

6. Faulmann, C.; Jacob, K.; Dorbes, S.; Lampert, S.; Malfant, I.; Doublet, M.-L.; Valade, L.; Real, J.A. Electrical conductivity and spin crossover: A new achievement with a metal bis dithiolene complex. Inorg. Chem. 2007, 46, 8548-8559. [CrossRef] [PubMed]

7. Takahashi, K.; Cui, H.-B.; Okano, Y.; Kobayashi, H.; Mori, H.; Tajima, H.; Einaga, Y.; Sato, O. Evidence of the chemical uniaxial strain effect on electrical conductivity in the spin-crossover conducting molecular system: $\left[\mathrm{Fe}^{\mathrm{III}}(\mathrm{qnal})_{2}\right]\left[\mathrm{Pd}(\mathrm{dmit})_{2}\right]_{5} \cdot$ acetone. J. Am. Chem. Soc. 2008, 130, 6688-6689. [CrossRef] [PubMed]

8. Djukic, B.; Lemaire, M.T. Hybrid Spin-crossover conductor exhibiting unusual variable-temperature electrical conductivity. Inorg. Chem. 2009, 48, 10489-10491. [CrossRef] [PubMed]

9. Nihei, M.; Takahashi, N.; Nishikawa, H.; Oshio, H. Spin-crossover behavior and electrical conduction property in iron(II) complexes with tetrathiafulvalene moieties. Dalton Trans. 2011, 40, 2154-2156. [CrossRef] [PubMed]

10. Phan, H.; Benjamin, S.M.; Steven, E.; Brooks, J.S.; Shatruk, M. Photomagnetic response in highly conductive iron(II) spin-crossover complexes with TCNQ radicals. Angew. Chem. Int. Ed. 2015, 54, 823-827. [CrossRef] [PubMed]

11. Zhang, X.; Wang, Z.-X.; Xie, H.; Li, M.-X.; Woods, T.J.; Dunbar, K.R. A cobalt(II) spin-crossover compound with partially charged TCNQ radicals and an anomalous conducting behavior. Chem. Sci. 2016, 7, 1569-1574. [CrossRef] 
12. Shvachko, Y.N.; Starichenko, D.V.; Korolyov, A.V.; Yagubskii, E.B.; Kotov, A.I.; Buravov, L.I.; Lyssenko, K.A.; Zverev, V.N.; Simonov, S.V.; Zorina, L.V.; et al. The conducting spin-crossover compound combining Fe(II) cation complex with TCNQ in a fractional reduction state. Inorg. Chem. 2016, 55, 9121-9130. [CrossRef] [PubMed]

13. Clemente-León, M.; Coronado, E.; López-Jordà, M.; Soriano-Portillo, A.; Waerenborgh, J.C.; Delgado, F.S.; Ruiz-Pérez, C. Insertion of a spin crossover FeIII complex into an oxalate-based layered material: Coexistence of spin canting and spin crossover in a hybrid magnet. Inorg. Chem. 2008, 47, 9111-9120. [CrossRef] [PubMed]

14. Neves, A.I.S.; Dias, J.C.; Vieira, B.J.C.; Santos, I.C.; Branco, M.B.C.; Pereira, L.C.J.; Waerenborgh, J.C.; Almeida, M.; Belo, D.; Gama, V. A new hybrid material exhibiting room temperature spin-crossover and ferromagnetic cluster-glass behavior. CrystEngComm 2009, 11, 2160-2168. [CrossRef]

15. Nihei, M.; Tahira, H.; Takahashi, N.; Otake, Y.; Yamamura, Y.; Saito, K.; Oshio, H. Multiple bistability and tristability with dual spin-state conversions in $\left[\mathrm{Fe}(\mathrm{dpp})_{2}\right]\left[\mathrm{Ni}(\mathrm{mnt})_{2}\right]_{2} \cdot \mathrm{MeNO}_{2}$. J. Am. Chem. Soc. 2010, 132, 3553-3560. [CrossRef] [PubMed]

16. Clemente-León, M.; Coronado, E.; López-Jordà, M.; Espallargas, G.M.; Soriano-Portillo, A.; Waerenborgh, J.C. Multifunctional magnetic materials obtained by insertion of a spin-crossover Fe ${ }^{\mathrm{III}}$ complex into bimetallic oxalate-based ferromagnets. Chem. Eur. J. 2010, 16, 2207-2219. [CrossRef] [PubMed]

17. Ohkoshi, S.; Imoto, K.; Tsunobuchi, Y.; Takano, S.; Tokoro, H. Light-induced spin-crossover magnet. Nat. Chem. 2011, 3, 564-569. [CrossRef] [PubMed]

18. Clemente-León, M.; Coronado, E.; López-Jordà, M.; Waerenborgh, J.C. Multifunctional magnetic materials obtained by insertion of spin-crossover $\mathrm{Fe}^{\mathrm{III}}$ complexes into chiral 3D bimetallic oxalate-based ferromagnets. Inorg. Chem. 2011, 50, 9122-9130. [CrossRef] [PubMed]

19. Roubeau, O.; Evangelisti, M.; Natividad, E. A spin crossover ferrous complex with ordered magnetic ferric anions. Chem. Commun. 2012, 48, 7604-7606. [CrossRef] [PubMed]

20. Clemente-León, M.; Coronado, E.; López-Jordà, M.; Waerenborgh, J.C.; Desplanches, C.; Wang, H.; Létard, J.-F.; Hauser, A.; Tissot, A. Stimuli responsive hybrid magnets: Tuning the photoinduced spin-crossover in Fe(III) complexes inserted into layered magnets. J. Am. Chem. Soc. 2013, 135, 8655-8667. [CrossRef] [PubMed]

21. Ababei, R.; Pichon, C.; Roubeau, O.; Li, Y.-G.; Bréfuel, N.; Buisson, L.; Guionneau, P.; Mathonière, C.; Clérac, R. Rational design of a photomagnetic chain: Bridging single-molecule magnets with a spin-crossover complex. J. Am. Chem. Soc. 2013, 135, 14840-14853. [CrossRef] [PubMed]

22. Fukuroi, K.; Takahashi, K.; Mochida, T.; Sakurai, T.; Ohta, H.; Yamamoto, T.; Einaga, Y.; Mori, H. Synergistic spin transition between spin crossover and spin-Peierls-like singlet formation in the halogen-bonded molecular hybrid system: $\left[\mathrm{Fe}(\mathrm{Iqsal})_{2}\right]\left[\mathrm{Ni}(\mathrm{dmit})_{2}\right] \cdot \mathrm{CH}_{3} \mathrm{CN} \cdot \mathrm{H}_{2} \mathrm{O}$. Angew. Chem. Int. Ed. 2014, 53, 1983-1986. [CrossRef] [PubMed]

23. Okai, M.; Takahashi, K.; Sakurai, T.; Ohta, H.; Yamamoto, T.; Einaga, Y. Novel Fe(II) spin crossover complexes involving a chalcogen-bond and $\pi$-stacking interactions with a paramagnetic and nonmagnetic $\mathrm{M}(\mathrm{dmit})_{2}$ anion ( $\mathrm{M}=\mathrm{Ni}$, Au; dmit = 4,5-dithiolato-1,3-dithiole-2-thione). J. Mater. Chem. C 2015, 3, 7858-7864. [CrossRef]

24. Ohkoshi, S.; Takano, S.; Imoto, K.; Yoshikiyo, M.; Namai, A.; Tokoro, H. 90-degree optical switching of output second-harmonic light in chiral photomagnet. Nat. Photonics 2014, 8, 65-71. [CrossRef]

25. Wang, C.F.; Li, R.-F.; Chen, X.-Y.; Wei, R.-J.; Zheng, L.-S.; Tao, J. Synergetic spin crossover and fluorescence in one-dimensional hybrid complexes. Angew. Chem. Int. Ed. 2015, 54, 1574-1577. [CrossRef] [PubMed]

26. Takahashi, K.; Cui, H.-B.; Kobayashi, H.; Einaga, Y.; Sato, O. The light-induced excited spin state trapping effect on $\mathrm{Ni}(\mathrm{dmit})_{2}$ salt with an $\mathrm{Fe}(\mathrm{III})$ spin-crossover cation: $\left[\mathrm{Fe}(\mathrm{qsal})_{2}\right]\left[\mathrm{Ni}(\mathrm{dmit})_{2}\right] \cdot 2 \mathrm{CH}_{3} \mathrm{CN}$. Chem. Lett. 2005, 34, 1240-1241. [CrossRef]

27. Takahashi, K.; Mori, H.; Kobayashi, H.; Sato, O. Mechanism of reversible spin transition with a thermal hysteresis loop in $\left[\mathrm{Fe}^{\mathrm{III}}(\mathrm{qsal})_{2}\right]\left[\mathrm{Ni}(\mathrm{dmise})_{2}\right] \cdot 2 \mathrm{CH}_{3} \mathrm{CN}$ : Selenium analogue of the precursor of an $\mathrm{Fe}(\mathrm{III})$ spin-crossover molecular conducting system. Polyhedron 2009, 28, 1776-1781. [CrossRef]

28. Duana, H.-B.; Ren, X.-M.; Meng, Q.-J. One-dimensional (1D) [Ni(mnt) $]^{-}$-based spin-Peierls-like complexes: Structural, magnetic and transition properties. Coord. Chem. Rev. 2010, 254, 1509-1522. [CrossRef]

29. Dickinson, R.C.; Baker, W.A.; Collins, R.L. The magnetic properties of bis[N-(8-quinolyl)-salicylaldimine] halogenoiron(III) $\times$ hydrate, $\mathrm{Fe}(8-\mathrm{QS})_{2} \mathrm{X} \cdot \mathrm{xH}_{2} \mathrm{O}$ : A reexamination. J. Inorg. Nucl. Chem. 1977, 39, 1531-1533. [CrossRef] 
30. Kobayashi, A.; Sasaki, Y. One-dimensional system of square-planar bis(1,2-dicyanovinylene-1,2-dithiolato) metal complexes. I. The crystal structure of $\left[\left(\mathrm{C}_{4} \mathrm{H}_{9}\right)_{4} \mathrm{~N}_{2}\left[\mathrm{Ni}(\mathrm{mnt})_{2}\right]\right.$ and $\left[\left(\mathrm{C}_{2} \mathrm{H}_{5}\right)_{4} \mathrm{~N}\right]\left[\mathrm{Ni}(\mathrm{mnt})_{2}\right]$. Bull. Chem. Soc. Jpn. 1977, 50, 2650-2656. [CrossRef]

31. Mori, T.; Kobayashi, A.; Sasaki, Y.; Kobayashi, H.; Saito, G.; Inokuchi, H. The intermolecular interaction of tetrathiafulvarene in organic metals. Calculation of orbital overlaps and models of energy-band structures. Bull. Chem. Soc. Jpn. 1984, 57, 627-633. [CrossRef]

32. Akutagawa, T.; Nakamura, T.; Inabe, T.; Underhill, A.E. Structures of Ni(dmit $)_{2}$ salts of lithium or ammonium included in crown ether assemblies. Thin Solid Films 1998, 331, 264-271. [CrossRef]

33. Akutagawa, T.; Nakamura, T. Control of assembly and magnetism of metal-dmit complexes by supramolecular cations. Coord. Chem. Rev. 2002, 226, 3-9. [CrossRef]

34. Ivanova, T.A.; Ovchinnikov, I.V.; Garipov, R.R.; Ivanova, G.I. Spin crossover $\left[\mathrm{Fe}(\mathrm{qsal})_{2}\right] \mathrm{X}(\mathrm{X}=\mathrm{Cl}, \mathrm{SCN}$, $\mathrm{CF}_{3} \mathrm{SO}_{3}$ ) complexes: EPR and DFT study. Appl. Magn. Reson. 2011, 40, 1-10. [CrossRef]

35. Zhou, H.; Wen, L.L.; Ren, X.M.; Meng, Q.J. Novel molecular staircases constructing from H-bonding interactions based on the building blocks of $\left[\mathrm{Ni}(\mathrm{mnt})_{2}\right]^{-}$ions: Syntheses, crystal structures, EPR spectra and magnetic properties. J. Mol. Struct. 2006, 787, 31-37. [CrossRef]

36. Hijmans, T.W.; Beyermann, W.P. Electron-spin-resonance study of the high-field phase of the spin-Peierls system tetrathiafulvalene-Au-bis-dithiolene. Phys. Rev. Lett. 1987, 58, 2351-2354. [CrossRef] [PubMed]

37. Yamamoto, Y.; Ohta, H.; Motokawa, M.; Fujita, O.; Akimitsu, J. The observation of $g$-shifts in spin-Peierls material $\mathrm{CuGeO}_{3}$ by submillimeter wave ESR. J. Phys. Soc. Jpn. 1997, 66, 1115-1123. [CrossRef]

38. Oshio, H.; Kitazaki, K.; Mishiro, J.; Kato, N.; Maeda, Y.; Takashima, Y. New spin-crossover iron(III) complexes with large hysteresis effects and time dependence of their magnetism. J. Chem. Soc. Dalton Trans. 1987, 1341-1347. [CrossRef]

39. Hayami, S.; Gu, Z.-Z.; Yoshiki, H.; Fujishima, A.; Sato, O. Iron(III) spin-crossover compounds with a wide apparent thermal hysteresis around room temperature. J. Am. Chem. Soc. 2001, 123, 11644-11650. [CrossRef] [PubMed]

40. Takahashi, K.; Mori, H.; Tajima, H.; Einaga, Y.; Sato, O. Cooperative spin transition and thermally quenched high-spin state in new polymorph of $\left[\mathrm{Fe}\left(\mathrm{qsal}_{2} \mathrm{I}_{3}\right.\right.$. Hyperfine Interact. 2012, 206, 1-5. [CrossRef]

41. Bousseksou, A.; Place, C.; Linares, J.; Varret, F. Dynamic spin crossover in $\left[\mathrm{Fe}(2-\mathrm{BIK})_{3}\right]\left(\mathrm{ClO}_{4}\right)_{2}$ and $\left[\mathrm{Fe}\left(\mathrm{Me}_{2} 2-\mathrm{BIK}\right)_{3}\right]\left(\mathrm{BF}_{4}\right)_{2}$ investigated by Mossbauer spectroscopy. J. Mag. Mag. Mater. 1992, 104-107, $225-226$. [CrossRef]

42. Maeda, Y.; Tsutsumi, N.; Takashima, Y. Examples of fast and slow electronic relaxation between ${ }^{6} \mathrm{~A}$ and ${ }^{2} \mathrm{~T}$. Inorg. Chem. 1984, 23, 2440-2447. [CrossRef]

43. Wignall, J.W.G. Mössbauer line broadening in trivalent iron compounds. J. Chem. Phys. 1966, 44, $2462-2467$. [CrossRef]

44. Summerville, R.H.; Hoffmann, R. Tetrahedral and other $\mathrm{M}_{2} \mathrm{~L}_{6}$ transition metal dimers. J. Am. Chem. Soc. 1976, 98, 7240-7254. [CrossRef]

45. Chen, M.M.L.; Hoffmann, R. Sulfuranes. Theoretical aspects of bonding, substituent site preferences, and geometrical distortions. J. Am. Chem. Soc. 1976, 98, 1647-1653. [CrossRef]

46. Jørgensen, K.A.; Hoffmann, R. Binding of alkenes to the ligands in $\mathrm{OsO}_{2} \mathrm{X}_{2}\left(\mathrm{X}=\mathrm{O}\right.$ and NR) and $\mathrm{CpCo}(\mathrm{NO})_{2}$. A frontier orbital study of the formation of intermediates in the transition-metal-catalyzed synthesis of diols, amino alcohols, and diamines. J. Am. Chem. Soc. 1986, 108, 1867-1876. [CrossRef]

47. Murata, S.; Takahashi, K.; Sakurai, T.; Ohta, H.; Yamamoto, T.; Einaga, Y.; Shiota, Y.; Yoshizawa, K. The role of Coulomb interactions for spin crossover behaviors and crystal structural transformation in novel anionic $\mathrm{Fe}(\mathrm{III})$ complexes from a $\pi$-extended ONO ligand. Crystals 2016, 6, 49. [CrossRef]

48. Murata, S.; Takahashi, K.; Sakurai, T.; Ohta, H. Single-crystal-to-single-crystal transformation in hydrogen-bond-induced high-spin pseudopolymorphs from protonated cation salts with a $\pi$-extended spin crossover Fe(III) complex anion. Polyhedron 2017. [CrossRef]

(C) 2017 by the authors. Licensee MDPI, Basel, Switzerland. This article is an open access article distributed under the terms and conditions of the Creative Commons Attribution (CC BY) license (http:/ / creativecommons.org/licenses/by/4.0/). 